\title{
DISERTACIONES
}

ENSAYOS

\section{LA MÚLTIPLE AUDIENCIACIÓN DE LAS SOCIEDADES CONTEMPORÁNEAS: DESAFÍOS PARA SU INVESTIGACIÓN*}

\section{The Multiple Audiencization of Contemporary Societies: Challenges for Research}

\section{A multíplice audiência das sociedades contemporâneas: desafios para sua pesquisa}

\author{
Guillermo Orozco Gómez, Universidad de Guadalajara
}

gorozco@cencar.udg.mx

Recibido: 08 de febrero de 2017

Aceptado: 21 de febrero de 2017

\section{RESUMEN}

Al reconocer que a la par de una mediatización creciente y diferenciada de las sociedades contemporáneas se desarrolla una audienciación múltiple y contrastante de los sujetos sociales, se sostiene en este ensayo que "ser y estar" como audiencia es la situación y actividad más característica de los ciudadanos hoy, y que es en esa interacción con el mundo, siempre mediada por representaciones audiovisuales de sí mismos, de los otros y de lo otro desde donde se construye y se juega la ciudadanía. El entendimiento de esta realidad es una razón sustantiva para su investigación, la cual se propone implementar a través de hacer evidente: i) los modos en que las representaciones mediáticas y digítales asumen a su audiencia; ii) la forma dominante o alternativa en que la audiencia es representada en las narrativas o en sus propias representaciones en los productos transmedia, y iii) la manera en que las audiencias son interpeladas desde las pantallas o por otras audiencias.

\footnotetext{
* En partes de este artículo se retoman extractos de otros textos del propio autor escritos recientemente.
} 


\title{
DISERTACIONES
}

Estudios de audiencias y recepción: audiencias minoritarias y nuevas mediaciones

ISSN: $1856-9536$

Doi: http://dx.doi.org/10.12804/revistas.urosario.edu.co/disertaciones/v11i1

Volumen 11, Número 1 / Enero-junio 2018

Versión PDF para imprimir desde

http://revistas.urosario.edu.co/index.php/disertaciones

Palabras clave: audiencias, representación mediática, transmediación, audienciación, mediaciones múltiples.

\begin{abstract}
Recognizing that along with a growing and differentiated mediatization of contemporary societies, a multiple and contrasting audiencing of social subjects is developed, this essay proposes that "to be" an audience is the most characteristic situation and activity of today's citizens. In this interaction with the world, always mediated by audiovisual representations of themselves and others, their citizenship is constructed. The understanding of this reality is a substantive reason for its research, which is proposed to be implemented through making evident: 1 . the ways in which media and digital representations assume their audiences; 2 . the dominant or alternative way in which the audience is represented in the narratives or in their own representations in transmedia products; and 3. the way in which the audiences are addressed from the screens or by other audiences.
\end{abstract}

Keywords: Audiences, media representation, transmedia, audiencing, multiple mediations.

\section{RESUMO}

Reconhecendo que junto à midiatização crescente e diferenciada das sociedades contemporâneas se desenvolve uma "audienciação" múltipla e contrastante dos sujeitos sociais, sustenta-se neste ensaio que "ser e estar" como audiência é a situação e atividade mais característica dos cidadãos hoje, e que nessa interação com o mundo, sempre mediada por representações audiovisuais de si mesmos, dos outros, e do outro, desde onde se constrói e se joga sua cidadania. $O$ entendimento desta realidade é uma razão substantiva para sua pesquisa, a qual propõe implementar através de fazer evidente: i) Os modos em que as representações midiáticas e digitais assumem a sua audiência; ii) A forma dominante, ou alternativa, em que a audiência é representada nas narrativas ou em suas próprias representações em seus produtos transmídia, e iii) A maneira em que as audiências são interpeladas desde as telas ou por outras audiências.

Palavras-chave: audiências, representação midiática, transmidiação, audienciação, mediação múltiplas.

\section{Introducción}

Si en la era industrial el ser trabajador y específicamente obrero fue la característica definitoria de las mayorías, hoy el ser audiencias múltiples de medios masivos y sociales es lo que mejor nos define e identifica como ciudadanos del siglo xxı. Habitamos un escenario en el que los tiempos de vigilia se desenvuelven cada vez más en relación 


\section{DISERTACIONES}

ENSAYOS

Estudios de audiencias y recepción: audiencias minoritarias y nuevas mediaciones

ISSN: 1856-9536

Doi: http://dx.doi.org/10.12804/revistas.urosario.edu.co/disertaciones/v11i1

Volumen 11, Número 1 / Enero-junio 2018

Versión PDF para imprimir desde

http://revistas.urosario.edu.co/index.php/disertaciones

a las pantallas, a veces con ellas, otras a partir de ellas, otras más hacia ellas y por ellas, lo que implica diferentes modos de vincularse, de "estar" como audiencias. Los procesos de contacto, intercambio, producción, recepción, uso, envío y transmediación a través de diversos canales, dispositivos y procedimientos analógicos y digitales constituyen cada día más, para más pobladores del mundo el epicentro de la actividad cotidiana.

La vida hoy es sobre toda "una experiencia mediática", enfatizan Press y Williams (2010), entendiendo por mediático no solo medios masivos audiovisuales, sino todo medio o dispositivo que ofrezca contenidos en cualquier lenguaje o combinación de ellos. Por esto, necesariamente a la par de la creciente mediatización contemporánea (Hjarvard, 2008) se extiende como su contraparte una "audienciación" significante y múltiple (Orozco, 2017), por la cual experimentamos lo que nos rodea siempre mediados por pantallas. "Ser audiencia", entonces, supone justamente eso, interactuar con el mundo y con los otros a través de sus representaciones, no de manera directa. La mayor, pero no única mediación, la han implantado los medios masivos del cine y la televisión. La televisión, y su heredero lo televisivo que está presente en las pantallas, nos cambió el modo de concebir y experimentar lo real, al hacer que lo percibido en pantallas fuera su representación y no lo representado (Carlón, 2014; Orozco, 2014). Pero ser audiencia no es propiedad exclusiva de la relación televisión-televidentes, aunque algunos estudiosos de la comunicación así lo hayan sugerido o lo consideren (Livingstone, 2003). Ser audiencia es un modo de realizar la ciudadanía contemporánea a través de múltiples mediaciones, crecientemente mediáticas, entretejidas en nuevos escenarios de interacción en y con el mundo real (Winocur, 2011).

\section{Audiencias, siempre audiencias}

Si bien como audiencias crecemos, como audiencias no nacemos, sino que nos hacemos o nos hacen de una determinada manera (Orozco, 2017), lo cual, independientemente de las "hechuras" es esperanzador, ya que incluye la condición sine qua non para poder evolucionar y ser audiencias de otras maneras, cuando se dan otras condiciones: audiencias más analíticas, más participativas, más conscientes y prevenidas ante los bombardeos de datos e imágenes que nos llegan desde las diversas pantallas.

El concepto "audiencia" es genérico y propio de los estudios de comunicación, más allá de que algunos prefieran hablar de consumidores y luego de "prosumidores" (Scolari, 2013). El término prosumidor, acuñado por Toffler en 1980, se ha puesto de moda en la bibliografía comunicativa, aunque desde los años setenta se haya manejado en los estudios latinoamericanos de audiencia y de alfabetización mediática el término de emirec, emisor-receptor (Cloutier, 1975), que no obstante su expresividad no prosperó como término de referencia de audiencias interactivas, quizá porque fue prematuro y estuvo más circunscrito a la televisión y los medios masivos, fuertemente unidireccionales. Por el contrario, ser prosumidores remite inmediatamente a la posmodernidad, y ha sido asumido por muchos investigadores para referir y distinguir esa doble participación creciente de las audiencias en relación a las pantallas y sus contendidos: una como consumidores y otra como productores o reproductores activos de contenido.

No obstante, y aunque García Canclini (2001) haya enfatizado desde una perspectiva culturalista que el consumo también sirve para pensar, desde la comunicación prosumidores como término sigue quedando corto ante la audienciación múltiple contemporánea. Así, lo más adecuado sería hablar de audiencias productoras o audiencias emisoras, que rebasan incluso el mero momento o acto de la producción para situarse en tanto productoras, 


\section{DISERTACIONES}

ENSAYOS

Estudios de audiencias y recepción: audiencias minoritarias y nuevas mediaciones

ISSN: 1856-9536

Doi: http://dx.doi.org/10.12804/revistas.urosario.edu.co/disertaciones/v11i1

Volumen 11, Número 1 / Enero-junio 2018

Versión PDF para imprimir desde

http://revistas.urosario.edu.co/index.php/disertaciones

como audiencias que se apropian, lo cual supone un proceso, no solo un acto de consumo, cuyo resultado incluye además de pensar, producir y enviar o reenviar, asumirse también en el rol activo de interlocutor en los procesos comunicativos. Se trata de un rol que contiene otra posición, otra decisión e implica otras destrezas e intencionalidades en lo comunicativo, ya que hay un nuevo posicionamiento de las audiencias como "emisoras" de contenidos, que van más allá de la mera producción, aunque esta sea su condición y sea también enormemente apreciada y deba promoverse por sí misma.

Las audiencias productoras rompen con la pasividad de la mera recepción, pero las audiencias emisoras asumen además el rol de interlocución y de participantes; roles tan necesarios hoy en día, por ejemplo para los nuevos movimientos sociales (Avalos, 2016).

Hay que recordar que las audiencias no han sido siempre como las hemos conocido frente a lo televisivo tradicional. Según el recuento de Butch (2000) en su singular libro: The Making of American Audiences: From Stage to Television, 1750-1990, las audiencias han tenido una "involución" de ser activas a ser contemplativas, lo que facilitó su tan criticada pasividad frente a los medios masivos, principalmente frente a la tv. Esto significó dejar de ser públicos activos y reaccionarios de "puestas en escena". Públicos demandantes, capaces de hacer modificar los libretos a sus directores y autores y sus actuaciones a los actores, o de debatir en la prensa escrita o producir la suya propia, para convertirse mayoritariamente en receptores/espectadores de las pantallas, sobre todo durante el "reinado" de la tv, que imperó por cinco décadas a partir de su inserción social generalizada en 1950 y que aún no acaba de desaparecer (Orozco \& Miller, 2016). Proceso, sin embargo, que quizá no empezó con la tv, aunque este medio lo haya acentuado de manera generalizada, sino con el cine como se interpreta de lo que comenta Monsiváis (1996) en uno de sus análisis sobre el vínculo de la sociedad moderna con la pantalla cinematográfica. Según Monsiváis, las audiencias se fueron deslumbrando con la magnificencia visual que el cinematógrafo les ofreció, por lo que sumergidas en cómodas butacas en las salas de cine, primero, admirando por primera vez en close up los bellos ojos o piernas de las estrellas de Hollywood, como Greta Garbo y Marlene Dietrisch, respectivamente, no se sintieron convocadas a nada más que a exclamaciones y suspiros ante la belleza que les mostraba la pantalla, lo que las dejó impactadas y motivadas para nada más que suspirar. Posteriormente los suspiros trascenderían el espectáculo cinematográfico, para surgir también del televisivo en la propia casa, lo que acabó por situar a las audiencias televisivas en un cómodo y pasivo rol, que ha durado medio siglo al menos, a lo largo del cual la evasión de la realidad a partir de lo visionado en las pantallas fue, y sigue siendo, una de las principales gratificaciones buscadas por las audiencias, y que según Miller (2010) seguirá siendo siempre una opción entre tantas otras maneras de ser audiencias más activas y proactivas.

\section{La "condición" comunicacional hoy}

El estar como audiencias pasivas y conformistas ha sido el resultado sobre todo de una forma particular de ser interpelados por las pantallas, no de una condición propia o de una necesaria característica intrínseca de la audienciación. La televisión comercial sobre todo, pero no únicamente, ya que la televisión pública o educativa también ha sido coincidente en esto aunque por diferentes razones, han interpelado a sus audiencias como conglomerados que debían obedecer lo que la pantalla les "dictaba". Lo que suponía que debían comportarse como audiencias pasivas y dóciles. Comprar y consumir los productos o servicios anunciados o aprender y asimilar los 


\section{DISERTACIONES}

ENSAYOS

Estudios de audiencias y recepción: audiencias minoritarias y nuevas mediaciones

ISSN: 1856-9536

Doi: http://dx.doi.org/10.12804/revistas.urosario.edu.co/disertaciones/v11i1

Volumen 11, Número 1 / Enero-junio 2018

Versión PDF para imprimir desde

http://revistas.urosario.edu.co/index.php/disertaciones

conocimientos o la información ofrecidos como insumos para salir de su ignorancia fueron los leit motiv dominantes en el establecimiento de un vínculo con las audiencias, vigente hasta hoy de manera generalizada en muchos países, y que sigue siendo el modus operandi de las empresas televisivas con amplios sectores de las audiencias, aun en la época en la que los nuevos dispositivos, pantallas y ventanas han cambiado su interpelación (Orozco, Navarro \& García, 2012).

La condición comunicacional de nuestro tiempo, implica esa "autocomunicación masiva" que describe Manuel Castells (2009) por la cual, no obstante la existencia accesible (para muchos) del inmenso aparato tecnológico existente para comunicarse, se siguen observando modos de comunicación pasados, verticales, planos, que más que enchufar a las audiencias las repelen o las obligan a aceptar dócilmente mensajes autoritarios, que bloquean su expresión y desarrollo de destrezas comunicativas horizontales.

Para la publicidad transmitida en la tv comercial y para la propaganda política transmitida en cualquier tipo de televisión y/o medio de comunicación, o para los contenidos educativos y culturales ofrecidos por las televisiones públicas o de proximidad (Orozco, 2017) lo importante ha sido "atrapar" a la audiencia, mantener su atención, persuadirla para que acepte sin reparos el mensaje emitido, evitar que en el proceso de recepción se interpongan barreras que le hagan desviar la mirada y la atención de la pantalla. El supuesto ha sido doble. Por una parte se ha asumido a una audiencia que puede manipularse, pero a la que no interesa involucrar, sino solo persuadir del mensaje ofrecido desde las pantallas. Por otra parte se ha concebido la relación medio-audiencias como una relación unilateral, en la que desde el emisor se envían mensajes para que la audiencia los acepte y los siga, mas no para que los discuta, rehaga o devuelva con sus opiniones (Orozco, 2010).

El caso del programa educativo Plaza Sésamo es muy ilustrativo y paradigmático de un tipo de vínculo buscado, por supuesto con los "mejores propósitos" de enseñanza-aprendizaje, entre un contenido televiso y sus audiencias, en este caso preescolares, que no obstante buscó mantener a su audiencia con los ojos fijos en la pantalla, como condición indispensable para que el mensaje educativo surtiera su efecto. En primer lugar, el formato educativo de Plaza Sésamo se ajustó más que a la racionalidad pedagógica de una enseñanza con un determinado grupo de aprendices-espectadores, a los requerimientos de tiempo y forma publicitarios de la televisión comercial que exigía ritmos y secuencias especificas idóneas para hacer cortes e insertar publicidad. Tiempos que tenían que ser respetados por los productores de los programas, aun a costa de los ritmos pedagógicos más apropiados para el aprendizaje. Así, los principios pedagógicos y las estrategias didácticas se supeditaron a los tiempos publicitarios, lo cual significó permitir que "el mercado se interpusiera en lo televisivo" entre la educación y las audiencias (Ortega et ál., 2010). Pero lo más sorprendente en el caso de esta programación educativa es que se buscó como condición pedagógico-televisiva para el aprendizaje, el que la audiencia infantil mantuviera los ojos fijos en la pantalla. Su mirada no podía desviarse para evitar el que se desenchufaran de la acción transmitida y así perdieran la secuencia que llevaría finalmente a un aprendizaje determinado. Para esto se hicieron desde la Universidad de Harvard, en la que Plaza Sésamo fue inventada desde la Facultad de Educación, estudios donde se medían las reacciones de las pupilas de niños televidentes a puntos opacos y luminosos en las pantallas. Con estos resultados se componía la iluminación y brillantez de las escenas de la serie para evitar lo más posible la distracción de los televidentes (Orozco, 2016).

Si con los grandes medios de comunicación en el escenario analógico las audiencias fueron mal acostumbrándose a no participar y se decantaron por jugar roles de recepción pasiva y escucha, roles de meras espectadoras, 


\section{DISERTACIONES}

ENSAYOS

Estudios de audiencias y recepción: audiencias minoritarias y nuevas mediaciones

ISSN: 1856-9536

Doi: http://dx.doi.org/10.12804/revistas.urosario.edu.co/disertaciones/v11i1

Volumen 11, Número 1 / Enero-junio 2018

Versión PDF para imprimir desde

http://revistas.urosario.edu.co/index.php/disertaciones

con lo digital la audiencia ya no tiene excusa para no asumir roles participativos e interactivos en sus intercambios comunicacionales, aunque no necesariamente se convierta en una audiencia activa (Crovi, 2006). La clave de su actividad, sin embargo, no depende solo ni principalmente de las características y variedad de las pantallas, sino de la interpelación que desde ahí se haga a través de los contenidos. No obstante, siempre estará la diferencia entre un televisor tradicional y una pantalla de teléfono móvil inteligente, que cada vez más se ha convertido en el epicentro de la interacción cotidiana de los ciudadanos-audiencia.

\section{Las audiencias, las nuevas pantallas y las posibilidades comunicativas}

La gran diferencia entre las pantallas del cine o la tv clásicas y las actuales: computadoras, tabletas, teléfonos inteligentes, en las que se pueden ver películas y programas televisivos, es que para las audiencias estas no son solo "simples pantallas" a través de las cuales mirar lo que otros transmiten, sino que son dispositivos personales en los cuales se puede trabajar y subir las propias producciones y distribuirlas, además de poder interactuar con lo que otros transmiten, no desde la pantalla principal, sino desde otros dispositivos (Aparici \& Silva, 2012). Lo anterior es un cambio sumamente importante, que erosiona lo televisivo clásico y abre inmensas posibilidades de asumir otros roles de productores y emisores en los procesos de comunicación e intercambio mediático y tecnológico. La "mesa está puesta" para una nueva interpelación de contenidos.

Lo que se ha inaugurado con la proliferación de las pantallas y la transmediación creciente sobre todo de la ficción audiovisual es una "multividencia" que rompe con la tradicional televidencia, siempre referida al televisor, en tanto que el vínculo con lo televisivo ya no es exclusivamente a través de la tv como medio/fuente principal.

El vínculo mediático múltiple de las audiencias se despliega con lo televisivo a través de diversas pantallas y dispositivos, por los que estas transitan; sitios todos donde las audiencias encuentran videos, películas y cualquier otro tipo de materiales audiovisuales, pero también textos escritos, música, grabaciones, etc., y por supuesto, las producciones de los fanes. En lo transmedia cabe todo, desde reformulaciones a un contenido en cualquier otro formato o lenguaje, hasta nuevos contenidos relacionados. De hecho, una parte de las ficciones de los aficionados son "ficciones de ficciones", realizadas, distribuidas y disfrutadas a través de sistemas de significación, lenguajes y empaquetamiento mediático variados (Scolari, 2013). Como sugiere Franco (2014) estamos frente a un escenario en el que las narrativas transmedia son una manera de hilvanar relatos, pensamientos e imaginaciones y poderlos compartir con otros "muchos" y retroalimentarlos permanentemente.

La gran mutación que se está realizando en el ámbito de la comunicación, los medios y sus audiencias es a fin de cuentas en la concepción misma de las audiencias, tanto por sí mismas como por los medios en sus propuestas e interacciones con ellas, y sobre todo en lo que se espera de ellas por parte de los productores de los nuevos contenidos. Lo cual conlleva a una transformación sustantiva del modo de interpelación en el escenario mediático-tecnológico actual. Aquí y así, las audiencias a su vez retoman nuevos roles o modos de estar frente a lo televisivo y lo cinematográfico o lo radiofónico o lo digital, lo cual en parte también es impulsado y facilitado por el avance tecnológico y la creciente estancia de las audiencias en escenarios digitales, donde son demandadas para reaccionar activamente y lo hacen, pero no solo desde los elementos convocantes específicos de su vínculo presente con un determinado contendido, sino también desde prácticas anteriores ejercidas por las audiencias 


\section{DISERTACIONES}

ENSAYOS

Estudios de audiencias y recepción: audiencias minoritarias y nuevas mediaciones

ISSN: 1856-9536

Doi: http://dx.doi.org/10.12804/revistas.urosario.edu.co/disertaciones/v11i1

Volumen 11, Número 1 / Enero-junio 2018

Versión PDF para imprimir desde

http://revistas.urosario.edu.co/index.php/disertaciones

en otras experiencias de producción de contenidos, como lo ha mostrado recientemente en su investigación el mexicano Corona (2017).

Para las audiencias el gran desafío es asumirse plenamente como interlocutoras de la producción mediática digital. Nunca se ha tenido como ahora la posibilidad técnica de producir contenidos propios y distribuirlos, y de acceder a las producciones de otros de manera horizontal con la posibilidad de intervenirlas y rehacerlas.

Curiosamente todo esto se ha hecho posible con un género programático que por lo menos en la academia y cultura ilustrada latinoamericanas ha sido considerado de segunda importancia (Martín-Barbero \& Rey, 1999), no obstante que los rating demuestren qué es el más visto: la ficción.

La ficción, y no la información ni la documentación de la realidad, se ha convertido en el súper genero televisual del siglo xxı (Orozco \& Vassallo, 2016). Es el nuevo epicentro de una interacción múltiple entre productores, emisores y audiencias activas en una cadena sin fin de creación e intercambio. Una de las características más interesantes de la ficción que está en juego hoy en día es la de ser un producto liberado de los protocolos clásicos de lo ficcional, tales como construcción de verosimilitud, serialidad, realismo de los personajes, y de las temáticas, lo cual seguramente liberará también la propia creatividad o capacidad inventiva de su noveles productores.

El caso de la serie Lost modificó la interpelación de su audiencia al abandonarla como mera espectadora y asumirla como necesaria "coautora" de la trama que se mostraba incompleta en la pantalla. La audiencia al no tener toda la secuencia de los acontecimientos en los capítulos de la serie, tenía que imaginarse cuáles habrían podido ser para que sucediera lo que sestaba sucediendo. De esta manera se estimula la creatividad reflexiva de la audiencia al impulsarla desde la pantalla a que encuentre y se imagine esas posibles o probables escenas que no se vieron pero que debieron haber ocurrido para que las que sí se mostraron adquieran o recuperen todo su sentido.

Lo anterior ha supuesto además de una nueva interpelación, una trasformación profunda de la manera de narrar, de contar "el cuento". Como advierte Piscitelli et ál. (2010): "en las series televisivas contemporáneas se encuentran fusiones de una historia en otras o una multiplicación de historias relacionadas por distintos motivos a una historia central, como sería el caso de la serie Lost" (p. 12). Esto tiene consecuencias en nuestra capacidad interpretativa, en nuestro reconocimiento de la causalidad mutua y en advertir y entender que algunos efectos crean sus propias causas y explican el movimiento de sus personajes en la historia contada.

Otro ejemplo de cambios en la ficción televisual es la serie House of Cards, donde el protagonista principal, el congresista Frank Underwood, personificado por el actor Kevin Spacey, entabla una relación intencionada, explícita y directa con los televidentes, ya que "los mira a los ojos" desde el televisor al comentar de vez en cuando lo que no dijo en su interacción con otros personajes, las razones por qué lo dijo o por qué hizo lo que hizo. De esta manera va fabricando una "complicidad" con la audiencia, quien se supone sabe, lo que otros protagonistas de la serie no. Este conocimiento le permite entender, anticipar y explicarse las actuaciones de otros personajes y el movimiento de la misma historia.

El desafío contemporáneo para los productores de ficción y para los productores de contenidos en general, sigue siendo enganchar a la audiencia por la trama misma, pero no por lo que monopolice y encapsule su atención, sino justamente por lo que la ensanche y la libere y aun por lo que la desafíe, así como por las posibilidades de extensión y transmediación que les permita. Esto supone la creación de vínculos más ocasionales que esenciales, pero finalmente efectivos y gratificantes para mantener a las audiencias inteligente y creativamente involucradas. 


\section{DISERTACIONES}

ENSAYOS

\section{Desafíos para la investigación de las audiencias múltiples}

Para los investigadores el desafío es inmenso por la explosión múltiple de la audiencia, de lo televisivo y de los formatos programáticos, en especial el abordado aquí de la ficción como género literario y contenido mediático, donde las posibilidades de enganchar con las audiencias se multiplican, incrementándose así las opciones de estar y de ser audiencias. Pero sobre todo, porque las audiencias actuales están en transición al escenario digital. Su tránsito es desigual de entrada, porque el acceso a las nuevas tecnologías así lo es (cEPAL, 2015), pero también porque ese tránsito no es siempre lineal, implica una gran variedad de saltos, vueltas y fragmentación de los tipos de vínculo que las audiencias entablan en su devenir entre la recepción, interacción, producción y emisión de contenidos referentes. Como atinadamente propone Repoll (2013): "sin caer en el pesimismo de los tecnofóbicos, subrayo la enorme brecha entre conectados y desconectados que condiciona la forma de ejercer la ciudadanía en la sociedad de la información, lo cual omiten ver los tecnofílicos" (p. 37).

Aunado a eso, la alfabetización mediática y digital general de las audiencias es precaria, sino inexistente, y es casi siempre irregular y diferenciada. Hay enormes huecos de capacitación digital, que impiden hacer el uso más sustantivo y no meramente instrumental, de los medios y tecnologías actuales y por tanto de sus productos comunicativos en general. Por ejemplo, unas preguntas para guiar una línea de investigación e intervención posible serían: ¿cómo transitar de la oralidad histórica de las culturas iberoamericanas a la "medialidad" contemporánea globalizada, donde no es la voz el canal principal de comunicación, sino la escritura: Facebook, Twitter, WhatsApp, Instagram, y la producción de imágenes significantes?, ¿qué tipo de información se requiere obtener de diversos sectores de audiencias para de ahí diseñar estrategias de intervención educativa en sus procesos mediático-tecnológicos que les permitan facilitar su tránsito al escenario tecnomediatizante de hoy en día y a la vez les facilite una adecuada inserción en él? En el fondo la pregunta que inspiraría esta línea de investigativa podría formularse así: ¿cómo empoderar a las audiencias para que dejen su rol pasivo y sumiso de espectadoras frente a los mensajes dominantes y se asuman interlocutoras en procesos horizontales de comunicación?

Pregunta y problema los anteriores, que convocan a los educadores para realizar una educomunicación más atinada, pero sobre todo a los investigadores de la comunicación y sus medios para explorar y eventualmente entender cómo y dónde, por ejemplo, se manifiestan las carencias expresivas y multilingüísticas de las audiencias. Indicadores, como alerta Ferres (2008), son necesarios para que las audiencias se inserten en procesos transmedia de interlocución y de esa manera reafirmen su ciudadanía activa en el mundo actual, sembrado de pantallas y prolífico en mensajes y difusión de productos audiovisuales.

En concordancia con lo aquí planteado, la propuesta de investigación de las audiencias tendría tres vertientes, que corresponden a las tres características mencionadas y que se están parcialmente modificando, pero que habría que acelerar y asegurar que se transformen en el sentido discutido en estas páginas. Estas tres líneas de investigación tendrían como objeto indagar: i) ¿Cómo se asume a la audiencia?; ii) ¿Cómo se le representa?, y iii) ¿Cómo se le interpela en y desde los diversos productos audiovisuales con los que entabla contacto?

Con respecto a lo primero, ¿cómo se asume a la audiencia?, se podrían explorar modos de asumirla a partir de disyuntivas específicas. Por ejemplo, si se la asume como espectadora o como participante, como ignorante o 


\section{DISERTACIONES}

ENSAYOS

Estudios de audiencias y recepción: audiencias minoritarias y nuevas mediaciones

ISSN: 1856-9536

Doi: http://dx.doi.org/10.12804/revistas.urosario.edu.co/disertaciones/v11i1

Volumen 11, Número 1 / Enero-junio 2018

Versión PDF para imprimir desde

http://revistas.urosario.edu.co/index.php/disertaciones

inteligente, como pasiva o activa, como objeto de ventas y/o persuasión o como sujeto capaz de discernir y argumentar, como interlocutora, como cómplice, como coautora del contenido, o como productora transmedia.

Tradicionalmente en la investigación sobre contendidos desde el campo académico de la comunicación y el estudio sobre medios se ha hecho énfasis en aspectos temáticos e ideológicos y más recientemente en detectar valores transmitidos específicamente por la programación televisiva (Orozco, 2010). Si bien estos estudios abonan en una comprensión mayor de los efectos o influencia posibles que ciertos programas pueden tener en audiencias determinadas y en la percepción de estas sobre lo que está en juego en la interacción social representada, no se enfocan en hacer evidente el tipo de concepción de audiencia de que se trata: se asume a la audiencia por defecto como espectadora. Como alguien externo al contenido, que a partir de ese visionado queda impactada de una u otra manera.

Con respecto al segundo gran interrogante: ¿cómo se representa a la audiencia desde las pantallas?, un interés específico de investigación sería obtener información sobre si los roles de los personajes mostrados en ellas son de ciudadanos desempoderados o empoderados, a partir de televidenciar situaciones donde esos personajes reproducen o por el contrario hacen evidentes roles tradicionales de subordinación o de negociación y asertividad por clase, género o raza. El cultivo dominante de la representación "normal" o real de reaccionar de los personajes en una historia narrada en la pantalla, al no mostrar opciones ni alternativas a una visión de dominación imperante en las relaciones sociales reales, las confirma.

Un ejemplo contemporáneo de representación alternativa de personajes es la película Hidden figures Talentos Ocultos- (2017) donde se muestra cómo tres mujeres negras talentosas fueron capaces de contribuir de manera contundente en la NASA al lanzamiento del primer hombre a la luna. La trama de la película muestra una serie de situaciones donde ellas son segregadas doblemente, por ser mujeres y por ser de raza negra, y muestra también cómo su gran inteligencia y sentido crítico sobre su segregación logra modificar su relación con el resto de compañeros de trabajo, todos hombres y blancos, hasta que el director del programa acaba convenciéndose de lo errático de un pensamiento racista y machista, y exclama: "en la NASA todos somos iguales, hombres y mujeres, negros y blancos". Aquí, indirectamente se está representando a una audiencia capaz de ser conmovida desde la película y capaz de transformar una creencia cultural imperante y arraigada en la sociedad norteamericana de los años sesenta.

La investigación que se ha realizado sobre el papel de la ficción en sus audiencias, por ejemplo por Igartua y Marcos (2015), abre un escenario nuevo de generación de conocimiento en la medida en que va explorando y descubriendo cómo es que la ficción televisiva tiene un mayor impacto en sus audiencias que otros tipos de programación. Impacto que se relaciona justamente con las formas en que la audiencia es asumida dentro de los relatos ficcionales.

En la misma línea, pero enfocándose en la audiencia infantil, el investigador chileno Valerio Fuenzalida (2013) sostiene que para que el niño-audiencia se contacte y relacione con un programa de televisión, este debe ser y verse representado dentro del programa. Esta es la recomendación sustantiva para cualquier programación infantil de calidad. Significa entre otras cosas, que al niño no hay que atraerlo con escenarios coloridos y música ni atraparlo con imágenes seductoras o efectos especiales, lo cual implica asumirlo fuera de la pantalla, asumirlo como espectador, más pasivo o menos pasivo, pero siempre fuera de la escena. El niño requiere sentirse dentro, necesita sentirse parte de la trama, tiene que ser genuinamente invitado, e incorporado a ella para que, entonces sí, se 


\section{DISERTACIONES}

ENSAYOS

Estudios de audiencias y recepción: audiencias minoritarias y nuevas mediaciones

ISSN: 1856-9536

Doi: http://dx.doi.org/10.12804/revistas.urosario.edu.co/disertaciones/v11i1

Volumen 11, Número 1 / Enero-junio 2018

Versión PDF para imprimir desde

http://revistas.urosario.edu.co/index.php/disertaciones

"siente a la mesa y coma", no invitado para que mire a los comensales y los vea comer, aunque verlos le pueda resultar entretenido. Lo anterior no supone una representación estereotipada del niño dentro de la trama. Supone que la trama esté desarrollada asumiendo su participación e involucramiento, para lo cual la trama misma "le hace lugar".

En el caso de la tv infantil, continúa Fuenzalida, un ejemplo simple es el programa Dora la exploradora, que sume a su audiencia infantil como testigo de ciertos acontecimientos que suceden en pantalla. En este programa de repente la protagonista, Dora, ve directamente a los niños y les hace preguntas sobre los demás personajes. Por ejemplo, les pregunta si han visto pasar a otro personaje o si saben a dónde fue o dónde está. Al menos eso supone que desde la pantalla los niños son tomados como audiencia activa a la cual se la involucra con preguntas directas y a la cual se la hace pensar en soluciones para los tropiezos de los personajes del programa. Como este ejemplo habrá que diseñar otros que conlleven la misma intencionalidad de involucrar de alguna manera a las audiencias, más allá de invitarlas o atraparlas como meras espectadoras de los cuentos y recuentos de las televisiones.

En relación al tercer cuestionamiento, ¿cómo se interpela a la audiencia?, este en parte comparte elementos de los interrogantes anteriores, pero busca explícitamente mover a la audiencia para producir, intercambiar y enviar lo producido a otros. Buscaría invitar y motivar a la audiencia a un ejercicio de story telling propio, a involucrarse en un intercambio con otros sujetos de la misma audiencia.

En esta dirección de reconstruir lo visto en una pantalla, habría que investigar cómo las audiencias desde su posición se sienten capaces de transformar la historia contada en la pantalla, y sobre todo qué elementos de las narrativas ficcionales consideran que les permiten transformar su papel en la historia, ya que esto es lo que les permite empoderarse frente a sí mismos, frente a los demás y frente a la misma historia.

Al mismo tiempo, dependiendo de los cuentos expuestos desde la pantalla, el rehacerlo supone rehacer las relaciones deseadas con los otros y con la trama misma y ser capaces de definir el desenlace o final de lo narrado. En esta recreación, los chicos y los grandes serán capaces también de modificar su relación con los pares, con los/ las de otro género, con los demás de la comunidad, con las autoridades y con sus propios subalternos y otros ciudadanos con los que tienen interacción. De esta manera, lo contado en la pantalla debe inspirar a las audiencias a rehacer, cambiar y recrear las situaciones vistas, de tal manera que les permita situarse como los "hacedores" y "protagonistas" de nuevas historias que podrían cobrar realidad, y donde ciudadanos concretos de la audiencia podrían ser sus héroes y heroínas.

Considerando lo anterior, un aspecto de exploración es justamente entender el movimiento emocional creativo de las audiencias, a veces pendular: a veces hacia adelante y otras hacia atrás. Un movimiento que puede ser implosivo lo cual hace su percepción más problemática o por el contrario lleno de explosiones lo cual puede llevar a diagnósticos erráticos.

La corriente transmedia, que se ha iniciado en la última década y que fue evidenciada por Jenkins (2009) y posteriormente elaborada por otros, entre ellos y muy productivamente por Scolari (2013) y más recientemente por el mexicano Corona, (2017) se ha convertido en una beta no solo interesante sino necesaria para alimentar la utopía de construir un mundo nuevo, distinto a los conocidos, donde sea la comunicación real el eje de la interacción ciudadana potenciado por la tecnología existente y los diversos procesos y productos posibles de construir e intercambiar. Si como sugiere la periodista Huffington (2011) la comunicación es el mayor entretenimiento de la gente hoy día, entendamos bien la comunicación y tengámosla como epicentro de la actividad ciudadana. 


\section{DISERTACIONES}

ENSAYOS

Estudios de audiencias y recepción: audiencias minoritarias y nuevas mediaciones

ISSN: 1856-9536

Doi: http://dx.doi.org/10.12804/revistas.urosario.edu.co/disertaciones/v11i1

Volumen 11, Número 1 / Enero-junio 2018

Versión PDF para imprimir desde

http://revistas.urosario.edu.co/index.php/disertaciones

¿Qué es lo que detona la producción transmedia de las audiencias?, ¿qué es lo que convoca su participación política y su involucramiento en redes y movimientos sociales?, son preguntas que no tienen fácil respuesta ni tampoco una única, pero que requieren irse contestando.

¿Por qué el personaje Harry Potter ha inspirado la producción de nuevas historias por parte de los que han visto sus películas?, ¿qué hay en este personaje y sus narrativas que invita y motiva a las audiencias a construir y contar otras a partir de las suyas? ¿Por qué los contenidos de las películas Star Wars han inspirado tantas historias más?, algunas en las que se cambian los personajes, otras en los que se transforman los escenarios de la acción. Otras más en las que se incluye a la audiencia explícitamente en algún rol protagónico. Estas preguntas, junto con otras, deben plantearse desde tradiciones académicas distintas a la de la comunicación o de cruces disciplinarios que se juzguen convenientes para iluminar desde otros enfoques y de maneras más complejas el gran fenómeno de la audienciación contemporánea.

\section{Últimas reflexiones}

Lo que he compartido en estas páginas obviamente lleva mucho de mi propia experiencia, visión y deseos, y responde en mucho a mis definiciones de objetos de estudio y preferencias de investigación dentro de la tradición de estudios de los medios y sus audiencias, y en espacial del enfoque de la Recepción. Enfoque que, no obstante, se asume críticamente y en conexión con el objetivo mayor de la perspectiva de educomunicación.

Lo propuesto en estas páginas se hilvana con hallazgos y reflexiones de otros colegas del área de estudios culturales, mediaciones, y estudios de la ficción televisiva independientemente de los énfasis de mi propia visión y de la perspectiva desde la que se ha desarrollado. Estoy convencido de que no podemos dejar de entender la audienciación y su contraparte, la mediatización, porque es precisamente en ese "estar siendo" audiencias como asumimos nuestro rol de ciudadanos y desde donde somos interpelados y podemos reinventarnos como tales. Pero es también desde nuestro ser y estar como audiencias donde enfrentamos nuevos e impredecibles desafíos para darle sentido a la ciudadanía, construir comunidad y hacer realidad una nueva socialidad y participación política.

Más allá de los efectos de los medios y las tecnologías contemporáneas, y más allá de las gratificaciones buscadas en ellos por las audiencias en los escenarios de cultivo y de significación predominantes, el explicar los vínculos reales y posibles que las audiencias entablan con viejos y nuevos medios y contendidos sigue siendo más que nunca una gran pregunta de investigación. Lo es porque explicar la construcción, el tipo y las alternativas de esos vínculos tiene el germen de la transformación de las relacione sociales y la construcción de la ciudadanía.

\section{Referencias}

1. Aparici, R., \& Silva, M. (2012). Pedagogía de la interactividad. Comunicar, 38, 51-58.

2. Avalos. J. (2016). Activismo político contemporáneo. Acción colectiva, jóvenes y tecnologías comunicativas en Guadalajara (Tesis de maestría. Universidad de Guadalajara: México).

3. Butch, R. (2000). The making of american audiences: from stage to television, 1750-1990. Cambridge University Press. 


\section{DISERTACIONES}

ENSAYOS

Estudios de audiencias y recepción: audiencias minoritarias y nuevas mediaciones

ISSN: 1856-9536

Doi: http://dx.doi.org/10.12804/revistas.urosario.edu.co/disertaciones/v11i1

Volumen 11, Número 1 / Enero-junio 2018

Versión PDF para imprimir desde

http://revistas.urosario.edu.co/index.php/disertaciones

4. Carlón, M. (2014). ¿Autopsia a la televisión? Dispositivo y lenguaje en el fin de una era. En M. Carlón, \& C. Scolari (coord.), El fin de los medios masivos. El debate continúa (pp. 183-210). Buenos Aires: La Crujía.

5. CEPAL: Comisión Económica para América Latina. (2015). Informe del estado de la banda ancha en América Latina y el Caribe 2015. Recuperado de http://repositorio.cepal.org/bitstream/handle/11362/38605/ S1500568

6. Castells, M. (2009). Comunicación y Poder. Madrid: Alianza Editorial.

7. Cloutier, J. (1975). L'Ere d'Emerec. Montreal: Presse de l'Université de Montréal.

8. Corona, J. (2017). Arqueología transmedia: participación de las audiencias en la expansión de las narrativas de la Segunda Guerra Mundial (caso Band of Brothers). adComunica. Revista de Estrategias, Tendencias e Innovación en Comunicación, 13, 176-199.

9. Crovi, D. (2006). Educar en la era de las redes. México: unam.

10. Ferrés i Prats, J. (2008). De la emoción por el consumo de emociones. Televisión, consumo y emociones. En I. Aguaded (Ed.), La otra mirada a la tele. Pistas para un consumo inteligente de la televisión (pp. 47-56). Madrid: Grupo Comunicar.

11. Francés, M. \& Orozco, G. (2016). Nuevos modelos mediáticos. Diversidad, usuarios y ventanas. Madrid: Editorial Síntesis.

12. Franco, D. (2014). Todo lo que usted siempre quiso saber sobre narrativa transmedia y nunca se atrevió a preguntar. Comunicación y Sociedad, 21, 305-309.

13. Fuenzalida, V. (2013). TV infantil: cambios en la narración y escritura de guiones. Conferencia Think Tank del Audiovisual-Fсом-Puc.

14. García Canclini, N. (2001). Consumidores y ciudadanos. Conflictos multiculturales de la globalización. México: Grijalbo.

15. Hjarvard, S. (2008). The mediatization of society. A theory of the media as agents of social and cultural change. Nordicom Review, 29(2), 105-134.

16. Huffington, A. (2011). Comunicar es el nuevo entretenimiento de la gente. Recuperado de http://tecnologia.elpais.com/tecnologia/2011/10/16/actualidad/1318755661_850215.html

17. Igartua, J. J., \& Marcos, M. (2015). Influence of character type and narrative setting on character design for fictional television series. Communication \& Society, 28(1), 63-77.

18. Jensen, K. (2014). La comunicación y los medios. Metodologías de investigación cualitativa y cuantitativa. México: Fondo Cultura Económica.

19. Jenkins, H. (2006). Convergence culture. Where old and new media collide. New York University Press.

20. Jenkins, H. (2009). Confronting the Challenges of Participatory Culture. Massachusetts: Miт Press.

21. Livingstone, S. (2003) The changing nature of audiences: From the mass audience to the interactive media user. En A. Valdivia (Ed.), Companion to media studies. Blackwell companions in cultural studies (pp. 337 359). Oxford: Blackwell Publishing.

22. Martín Barbero, J. \& Rey, G. (1999). Los ejercicios del ver. Hegemonía audiovisual y ficción televisiva. Madrid: Gedisa.

23. Miller, T. (2010). Television studies: The basics. Londres: Routledge.

24. Monsiváis, C. (1996). Aires de familia. México: Nueva Imagen. 


\section{DISERTACIONES}

ENSAYOS

25. Orozco, G. (2010). Audiencias ¿siempre audiencias? Hacía una cultura participativa en las sociedades de la comunicación. Ponencia presentada en La Conferencia Inaugural Del XXII Encuentro Nacional Amıc, México.

26. Orozco, G., Navarro, E., \& García, A. (2012). Desafíos educativos en tiempos de auto-comunicación masiva: la interlocución de las audiencias, Comunicar, 38, 67-74.

27. Orozco, G. (2014). La televisión, lo televisivo y sus audiencias: El estallido con sus vínculos con la ficción. TELOS, 99, 13-22.

28. Orozco, G. (2014b). tv: causa y efecto de sí misma. En M. Carlón \& C. Scolari (Coords.), El fin de los medios masivos. El debate continúa (pp. 229-244). Buenos Aires: La Crujía.

29. Orozco, G. (2015). Mexican research on tv: A tradition framed by a powerful quasi-monopolist tv system. En M. Alvarado, M. Buonanno, H. Gray, \& T. Miller (Eds.), The sage handbook of television studies (pp. 105-114). Londres: Sage.

30. Orozco, G. (2016). Por una creatividad televisiva que empodere a sus audiencias. En G. Orozco (Coord.), TvMorfosis 5. La creatividad en la era digital (pp.181-194). Guadalajara: UdeG/Tintable.

31. Orozco, G., \& Miller, T. (2016). Television in Latin America in "Everywhere": Not dead, not dying, but converging and thriving. Media and Communication, 4(3), 99-108.

32. Orozco, G., \& Vassallo, I. (2016). Obitel 2016. (Re)invención de géneros y formatos de la ficción televisiva. Sao Paulo: Globo.

33. Orozco, G. (2017). Un nuevo vínculo con las audiencias, el gran desafío para la televisión de proximidad. En M. Francés \& G. Orozco (Comps.), La televisión de proximidad en el entorno transmedia (pp. 14-21). Madrid: Editorial Síntesis.

34. Ortega et al. (2010). Comunicación y educación. Enfoques desde la alternatividad. México: uam/Porrúa.

35. Piscitelli, A. et al. (2010). Lostología. Estrategias para entrar y salir de la isla. Buenos Aires: Cinema.

36. Press, A., \& Williams, B. (2010). The new media environment: An introduction. Oxford: Wiley-Blackwell.

37. Repoll, J. (2010). Arqueología de los estudios culturales de audiencia. México: UACM.

38. Repoll, J. (2013). La ilusión de la participación. Volver a las mediaciones: del otro lado a muchos lados. En G. Orozco (Coord.), TvMorfosis 2. Convergencia y escenarios para una televisión interactiva (pp. 37-54). México: UdeG/Tintable.

39. Scolari, C. (2013). Narrativas Transmedia. Cuando todos los medios cuentan. Barcelona: Deusto-Grupo Planeta.

40. Toffler, A. (1980). La tercera ola. Bogotá: Círculo de Lectores/Plaza y Janés.

41. Winocur, R. (2011). Ciudadanos mediáticos: la construcción de lo público en la radio. Barcelona: Gedisa. 